\title{
Comparing the effect of three denture adhesives on the retention of mandibular complete dentures for diabetic patients (randomized clinical trial)
}

\author{
Eman Mostafa Ahmed Ibraheem ${ }^{*}$ and Ahmed Mostafa Esmat El-sisy
}

\begin{abstract}
Retention is an important parameter in the success of the prosthodontic treatment. Retention depends upon numerous factors such as physical, physiological, psychological, mechanical, and surgical factors. Denture adhesives increase the retention and stability of complete dentures. Denture adhesives have many indications such as immediate dentures, flat ridges, and patients with xerostomia and poor muscle control.

Aim of study: The present in vivo clinical study evaluates whether the adhesives used are truly effective to improve the mandibular complete denture retention for low well-rounded mandibular ridges in controlled diabetic patients.

Materials and methods: An in vivo clinical study is made of 30 male completely edentulous patients with low well-rounded mandibular ridges with an age group of 50-70 years were selected. All patients were controlled diabetic type 2. New complete dentures were constructed for them. The universal testing machine was used to measure forces required to dislodge the dentures. Retention of mandibular complete dentures was measured without adhesive and with the use of three types of denture adhesives after adaptation period of 1 month. A paste type (Fittydent) and two cream types (Protefix and Corega) were used. The average records after $15 \mathrm{~min}, 1 \mathrm{~h}$, and $2 \mathrm{~h}$ were recorded.

Results and conclusion: This study revealed that denture adhesives increase retention of complete dentures. Fittydent adhesive paste was more effective in improving the retention than Protefix and Corega adhesive creams. Therefore, denture adhesives improve patient satisfaction.
\end{abstract}

Keywords: Retention, Denture adhesive, Mandibular complete dentures, Diabetic patients

\section{Introduction}

Adequate retention constitutes an elementary and main quality for satisfying the patient with the complete dentures (Al- Abdulla \& Khamas, 2009). The retention of complete dentures may be influenced by a number of variables classified by Hardy and Kapur (1958) as physical, physiological, psychological, mechanical, and surgical factors. Improving retention and stability of dentures is of a substantial attention in dental prosthesis (Hardy \& Kapur, 1958). Over dentures, implants, ridge augmentation, vestibuloplasty, surface treatment of polymethyl methacrylate

\footnotetext{
* Correspondence: eman1mostafa@yahoo.com

Removable Prosthodontics, National Research Centre, Cairo, Egypt
}

denture base material, and denture adhesives were considered to overcome the problem of retention (Yen et al., 2013).

Denture adhesives increase denture retention and stability, thereby improving mastication and speech, reducing in denture medio-lateral movement, reducing collection of food particles under the dentures, reducing the growth of candida, and improving patients comfort, confidence, and satisfaction. Patients should be instructed about the correct use of adhesives as a part of denture post-delivery instruction (Figueiral et al., 2011).

The increased stability and retention allow denture patients to increase the force exerted during mastication, 
which results in less chewing strokes to reach the swallowing stage. The use of denture adhesives provides a cushioning effect that helps to distribute the occlusion forces over the denture-bearing areas, thereby minimizing local pressure points (Yadav \& Yadav, 2005).

Denture adhesives are indicated for many cases such as severely atrophied edentulous ridges of severe grade, severely abused/hypertrophied tissue covering the ridges, immediate dentures, patients having lack of neuromuscular control (e.g., stroke and Parkinsonism), cases with xerostomia, maxillofacial defects which provides inadequate tissue support, and patients with lack of neuromuscular control (Muneer et al., 2013).

Denture adhesives are marketed in many forms such as powders, paste creams, semi-viscous liquids, thin sheets, and wax-impregnated adhesive cloths (cushion). However, the powder, paste, and liquid forms are the widely used forms. A number of studies have been conducted to evaluate the efficiency of the denture adhesives in improving denture retention and measured either subjectively or by determining the force required to displace the dentures (Salman \& Ibrahim, 2005).

Diabetes mellitus is a chronic metabolic disorder characterized by hyperglycemia, associated with irregularities in the metabolism of carbohydrates, lipids, and proteins, and susceptibility to the development of specific forms of premature renal, ocular, neurological, and cardiovascular diseases (Rahman, 2013). Non-insulindependent type 2 diabetes generally occurs after the age of 40, and its prevalence increases with age. Type 2 diabetes has a non-immune cause (no destruction of pancreatic island cells), and it has been related to a genetic background, as well as to obesity and stress conditions. Diabetes mellitus is one of the most prevalent diseases and is commonly found in dental patients (Turkyilmaz, 2010; Diagnosis and Classification of Diabetes Mellitus. American Diabetes Association, 2010).

Oral manifestations of diabetes mellitus are numerous such as ketonic breath, periodontal disease, gingival recession, residual bone resorption, periodontal abscess, gingival overgrowth, vascular alterations, candidiasis, and xerostomia (Mauri-Obradors et al., 2017). The oral mucosa also loses resiliency, which is necessary for good adaptation to the complete dentures. Retention of complete dentures for diabetic patients was less than non-diabetic patients, since diabetes increases the osteoclastic activity of the bone in the mandible and maxilla (Kansal \& Goyal, 2013). Hyposalivation is significantly associated with depression and anxiety. Wettability, surface tension, viscosity, and muscle control are factors that enhance denture retention. The use of some medications such as anti-depressive, antihypertensive, and diuretic agents may alter the salivary gland secretion (Soman \& Bhatnagar, 2014).
This study aimed to determine and compare the effect of the use of three types of paste denture adhesives on the retention of newly fabricated mandibular complete dentures for diabetic patients by an in vivo method using a universal testing machine.

\section{Methods}

Thirty male completely edentulous patients, with their ages ranged from 50 to 70 years, were included in this study. All selected patients were controlled diabetic type 2 without former dentures. They have low well-rounded mandibular ridges covered with firm healthy mucosa without any signs of inflammation or flabby tissues, normal jaw relationships, normal tongue size, and normal temporomandibular joint function. Smokers and patients suffering from xerostomia were excluded. An informed consent form was signed by all patients before treatment.

A heat-cured acrylic resin complete denture was constructed for each patient in a conventional manner. $\mathrm{Pa}$ tients were informed to use their new dentures for 1 month as an adaptation period.

\section{Instructions for application of denture adhesive for all patients}

- The fitting surface of the denture must be clean and dry before application of the adhesive. The patients were instructed to use the Fittydent cleansing tablets that were given to them, before each application.

- The adhesive should be kept at room temperature, and it is preferred to warm the tube in the hands for a short time before application.

- The patients were instructed to apply little amount of the adhesive on a previously prespecified spots on the fitting surface and away from the edge of the denture and patients must be asked to close firmly in centric occlusion\& hold in place for few seconds to wait for 15 minutes before starting the adhesive testing.

- The applied amount varies from 0.15 to $1 \mathrm{~g}$ depending on the physical preparation of the adhesive and on the size of the individual denture.

- The tube must be tightly and immediately closed after each application and the nozzle of the tube must be clean.

Retention was measured using a universal testing machine (Fig. 1). The retention was measured according to Van Kampen et al., (2003) and Ashour et al, (2010) (Duqum et al., 2012; Salman, 2001). 

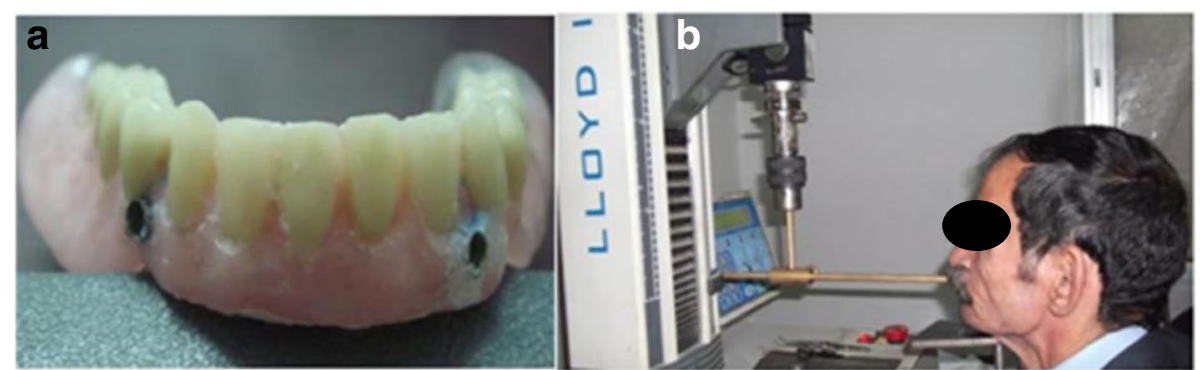

Fig. 1 a Prepared mandibular denture for measuring retention. b Measuring mandibular denture retention using a universal testing machine

\section{Modifications in the denture}

Two small metal tubes (3-mm diameters) were placed a few millimeters underneath the premolars in the mandibular denture. The dentures were rigidly and reproducibly connected to two pins in the horizontal metallic arm and turned to the universal testing machine.

\section{Technique for measuring retention}

After a 1-month adaptation period, the patient was instructed to sit down in an upright position and his chin firmly seated on a chin support on the testing machine. The bar was rigidly connected to the denture. Vertical dislodging force (expressed in Newton) applied by the universal testing machine increased gradually until dislodgement of the denture occurred. The test was repeated three times and the average of these records was taken every time during the follow-up period.

Retention of mandibular complete dentures was assessed after a 1-month adaptation period without the use of adhesive; this served as the control. The first adhesive was applied, and average records after $15 \mathrm{~min}, 1 \mathrm{~h}$, and $2 \mathrm{~h}$ were recorded. Then, the denture was cleaned and kept in water for the second day. The second adhesive was applied on the second day, and average records were recorded after $15 \mathrm{~min}, 1 \mathrm{~h}$, and $2 \mathrm{~h}$. The third adhesive was applied on the third day, and average records were recorded after $15 \mathrm{~min}, 1 \mathrm{~h}$, and $2 \mathrm{~h}$. After finishing the measurements, the metallic tubes were removed and the denture was polished and returned to the patient.

\section{Statistical analysis}

Statistical analysis was performed with SPSS 13.0. Data were presented as mean and standard deviation. The least significance difference test (LSD) was consequently executed. This test was conducted to determine which of the groups showed significant differences. A $P$ value less than 0.05 was considered as the level at which statistical significance exists.

\section{Results}

The mean and standard deviation of measurements of dislodgement forces of a poorly fitted mandibular complete denture without a denture adhesive and at various time intervals with the use of the denture adhesives (Table 1) (Al- Abdulla \& Khamas, 2009) revealed that the mean of dislodgement forces was increased with the use of the denture adhesives and the denture adhesives showed an

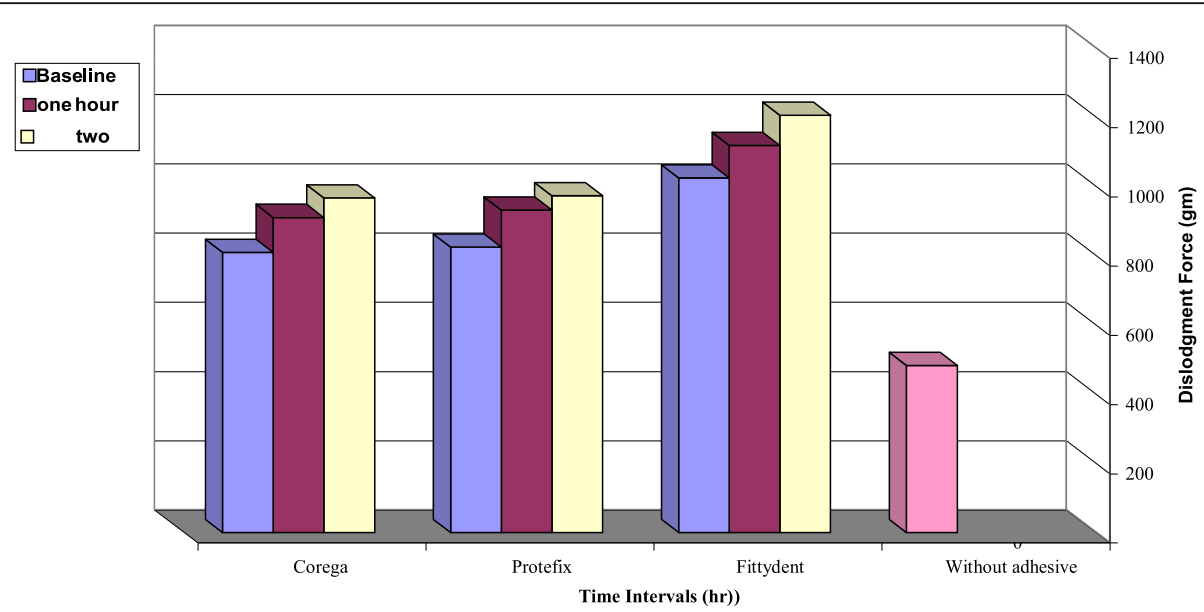

Fig. 2 Mean dislodgement forces of poorly fitting mandibular complete dentures with saliva alone and at various time intervals with the use of denture adhesives 
Table 1 Mean dislodgement forces in grams with standard deviation of poorly fitting mandibular complete dentures without adhesive and at various time intervals with the use of denture adhesives

\begin{tabular}{|c|c|c|c|c|c|c|c|}
\hline & & Mean & SD & SE & Min & Max & C.V\% \\
\hline Without adhesive & & 483.1 & 54.872 & 17.352 & 395 & 577 & 11.358 \\
\hline \multirow[t]{3}{*}{ Fittydent adhesive paste } & Baseline & 1024.2 & 81.194 & 25.676 & 918 & 1177 & 7.927 \\
\hline & $1 \mathrm{~h}$ & 1119.3 & 85.69 & 27.10 & 1018 & 1277 & 7.656 \\
\hline & $2 \mathrm{~h}$ & 1207 & 76.540 & 24.204 & 1090 & 1312 & 6.341 \\
\hline \multirow[t]{3}{*}{ Protefix adhesive cream } & Baseline & 825.9 & 58.847 & 18.609 & 723 & 919 & 7.125 \\
\hline & $1 \mathrm{~h}$ & 931.6 & 48.277 & 15.266 & 858 & 1011 & 5.182 \\
\hline & $2 \mathrm{~h}$ & 973.1 & 48.367 & 15.295 & 890 & 1020 & 4.970 \\
\hline \multirow[t]{3}{*}{ Corega adhesive cream } & Baseline & 810.5 & 54.195 & 17.138 & 736 & 911 & 6.686 \\
\hline & $1 \mathrm{~h}$ & 911.3 & 47.609 & 15.05 & 839 & 996 & 5.224 \\
\hline & $2 \mathrm{~h}$ & 967.3 & 73.87 & 23.36 & 873 & 1110 & 7.636 \\
\hline
\end{tabular}

increase in the denture retention with increase of the time of the experiment.

The Fittydent adhesive has higher dislodgement values when compared with the other adhesives after 2-h time intervals (Fig. 2).

Using paired Student's $t$ test for the different values of dislodgement forces revealed that there is a highly significant difference, $P<0.0001$, in the amount of retention for all types of adhesives compared to its values without adhesives during all time intervals (Table 2).

Student's paired $t$ test was used to make a comparison between the dislodgement values of the three types of denture adhesives (Fittydent, Protefix, and Corega) at different time intervals (Table 3).

The results showed that there is a highly significant difference, $P<0.0001$, when comparing between Fittydent and Protefix denture adhesives and also between the Fittydent and Corega denture adhesives while there is a non-significant difference, $P>0.05$, between the Protefix and Corega denture adhesives at the baseline and 1-h and 2-h time intervals.

\section{Discussion}

Denture adhesives are used to improve the retention and stability of complete dentures (Duqum et al., 2012).

In the present study, denture adhesives significantly increase denture retention at all time intervals $(P<0.0001)$, and this is in agreement with Salman (2001).

The main components of denture adhesives are either vegetable gum or synthetic polymer as carboxymethyl cellulose and polyvinyl methyl ether maleate. As the adhesive absorbs water and the carboxymethyl cellulose comes in contact with the saliva, the hydrate material (free carboxyl groups) is formed and swells greater than their original volume, thereby excluding air between denture bases and bearing tissue. The hydrate material sticks to the fitting surface of the denture and oral mucosa and increases the viscosity of the saliva. These actions increase the retention of complete dentures. Free carboxyl groups formed by the wetting of adhesives such as methyl cellulose or hydroxyl methyl cellulose, form electrovalent bonds that produce stickiness or strong bioadhesive forces (Kumar \& Shajahan, 2015).

The three types used of denture adhesives used instantly started increasing retention; their effectiveness increased progressively from the baseline, and maximum retention was attained after $2 \mathrm{~h}$. Saliva could not flow definitely into the space between the denture base and mucosa. Also with the increase of time, the salivary flow decreases (Floystrand et al., 1991; Grasso et al., 1994).

Fittydent recorded higher dislodging values which were of highly significant difference $(P<0.0001)$ when compared with Protefix and Corega throughout all time intervals, while both Protefix and Corega showed no significant difference $(P>0.05)$ when compared with each other throughout all time intervals (Rendell et al., 2000).

The insoluble Fittydent adhesive paste had higher values of displacing forces when compared with Protefix and Corega adhesive creams which make it not affected by saliva and liquids. The insoluble Fittydent provides strong bioadhesive and cohesive forces between the polyvinyl group and

Table 2 Comparison of dislodgement forces of poorly fitting mandibular complete dentures without adhesive and with the use of three types of denture adhesives at various time intervals (Student's paired $t$ test)

\begin{tabular}{|c|c|c|c|c|c|c|}
\hline & \multicolumn{2}{|c|}{ Fittydent } & \multicolumn{2}{|c|}{ Protefix } & \multicolumn{2}{|c|}{ Corega } \\
\hline & $t$ test & $P$ value & $t$ test & $P$ value & $t$ test & $P$ value \\
\hline Immediate & 17.46 & 0.000 & 13.47 & 0.000 & 13.42 & 0.000 \\
\hline $1 \mathrm{~h}$ & 19.77 & 0.000 & 19.41 & 0.000 & 18.64 & 0.000 \\
\hline $2 \mathrm{~h}$ & 24.31 & 0.000 & 21.18 & 0.000 & 16.64 & 0.000 \\
\hline
\end{tabular}

${ }^{*} P<0.0001$, highly significant 
Table 3 Comparison of effectiveness among the denture adhesives at each time intervals (Student's paired $t$ test)

\begin{tabular}{|c|c|c|c|c|c|c|}
\hline & \multicolumn{2}{|c|}{ Immediately } & \multicolumn{2}{|l|}{$1 \mathrm{~h}$} & \multicolumn{2}{|l|}{$2 \mathrm{~h}$} \\
\hline & $t$ test & $P$ value & $t$ test & $P$ value & $t$ test & $P$ value \\
\hline Fittydent and Protefix & 6.25 & $\begin{array}{l}0.000 \\
\mathrm{HS}\end{array}$ & 6.03 & $\begin{array}{l}0.000 \\
\mathrm{HS}\end{array}$ & 8.17 & $\begin{array}{l}0.000 \\
\text { HS }\end{array}$ \\
\hline Fittydent and Corega & 6.92 & $\begin{array}{l}0.000 \\
\mathrm{HS}\end{array}$ & 6.71 & $\begin{array}{l}0.000 \\
\mathrm{HS}\end{array}$ & 7.13 & $\begin{array}{l}0.000 \\
\mathrm{HS}\end{array}$ \\
\hline Protefix and Corega & 0.61 & $\begin{array}{l}0.55 \\
\text { NS }\end{array}$ & 0.95 & $\begin{array}{l}0.36 \\
\text { NS }\end{array}$ & 0.21 & $\begin{array}{l}0.84 \\
\text { NS }\end{array}$ \\
\hline
\end{tabular}

${ }^{*} P<0.0001$, highly significant

${ }^{* *} P>0.05$, non-significant

the carboxymethyl cellulose. The carboxymethyl cellulose provides a quick hold and the polyvinyl group holds it for a long interval, and thus it increases the retention of mandibular complete dentures (Yegin et al., 2017).

The hydrate material formed by carboxymethyl cellulose stay intact because of the insoluble properties of the Fittydent denture adhesive paste, this action delays the washing away of the polymer by the salivary flow so that the effective life of the polymer during use is increased, thereby markedly increasing the retention of mandibular complete dentures (AL-Loaibi, 2004; J1 et al., 2000).

Denture adhesives improved the retention of the dentures more so for poorly fitting dentures than well-fitting dentures (Chew et al., 1985).

\section{Conclusion}

This study revealed that denture adhesives increase retention of complete dentures. The Fittydent adhesive paste was more effective in improving the retention than the Protefix and Corega adhesive creams. Therefore, denture adhesives improve patient satisfaction.

\section{Acknowledgements}

The authors thank the National Research Centre, Cairo, Egypt for supporting this study.

\section{Funding}

This research was funded form National Research Centre, Cairo, Egypt, in a project no. 11010203 entitled "Dental Care to improve quality of life for diabetic geriatric patients"

\section{Availability of data and materials}

This article under the terms of the Creative Commons AttributionNonCommercial- NoDerivs License, which permits use and distribution in any medium, provided the original work is properly cited, the use is noncommercial and no modifications or adaptations are made. Materials were available in the market and data was collected in a smooth manner

\section{Authors' contributions}

Both authors contributed to this project and article equally. All authors read and approved the final manuscript.

\section{Ethics approval and consent to participate}

The study protocol was approved by the Ethics Committee of the National Research Center, Cairo, Egypt. All patients were informed thoroughly about the study, and each patient was asked to sign a consent form. Only motivated and cooperative patients who accepted the periodic recall visits and agreed to sign the consent form were enrolled.

Ethical approval will be attached

\section{Consent for publication}

Will be attached

\section{Competing interests}

The authors declare that they have no competing interests.

\section{Publisher's Note}

Springer Nature remains neutral with regard to jurisdictional claims in published maps and institutional affiliations.

Received: 1 November 2018 Accepted: 9 January 2019

Published online: 12 February 2019

\section{References}

Al- Abdulla IH, Khamas AM (2009) The effect of three different denture adhesives on the retention of mandibular complete denture (Comparative study). J Bagh College Dentistry. 21(2):5-9

AL-Loaibi MA (2004) The effect of palatal reduction of the maxillary complete denture on the retention and patient satisfaction. M.Sc.D thesis, college of dentistry. In: university of Baghdad

Ashour M (2010) Evaluation of single symphseal implant. MD thesis. Faculty of Dental Medicine Al-Azhar University

Chew LC, boone ME, Swartz ML, Phillips RW (1985) Denture adhesives: their effect on denture retention and stability. J Prosthet Dent. 13:152-159

Diagnosis and Classification of Diabetes Mellitus. American Diabetes Association. Diabetes care, vol.33, (1), 2010

Duqum I, Powers KA, Cooper L, Felton D (2012) Denture adhesive use in complete dentures: clinical recommendations and review of the literature. Gen Dent 60(6):467

Figueiral MH, Fonseca PA, Pereira-Leite C, Scully C (2011) The effect of different adhesive materials on retention of maxillary complete dentures. Int J Prosthodont. 24(2):175-177

Floystrand F, Koppang R, Williams VD, Orstavik J (1991) A method for testing denture adhesives. J Prosthet .Dent. 66:501-504

Grasso JE, Rendell J, Gay T (1994) Effect of denture adhesive on the retention and stability maxillary dentures. J Prosthet. Dent 72(4):399-405

Hardy IR, Kapur KK (1958) Posterior border seal, its rational and importance. J Prosthet Dent. 8:386-398

J G, Gay T, Rendell J, Baker R, Knippenberg S, Finkeldey J, Zhou X, Winston JL (2000) Effect of denture adhesive on retention of the mandibular and maxillary dentures during function. J Clin Dent. 11(4):98-103

Kansal G, Goyal D (2013) Prosthodontic Management of Patients with Diabetes Mellitus. J Adv Med Dent Scie Res 1(1):38-44

Kumar PR, Shajahan PA, Mathew J, Koruthu AAP, Ahammed MF (2015) Denture Adhesives in Prosthodontics: An Overview. J Int Oral Health. 7(Suppl 1):93-95

Mauri-Obradors E, Estrugo-Devesa A, Jané-Salas E, Viñas M, LópezLópez J (2017) Oral manifestations of Diabetes Mellitus. A systematic review. Med Oral Patol Oral Cir Bucal. 22(5):e586-e594

Muneer MU, Ahmed AR, Kamran MF (2013) Awareness of dentists and complete wearers towards denture adhesives. Pakistan Oral \& Dental Journal 33(1):192-194

Rahman B (2013) Prosthodontic concerns in a diabetic patient. Int J Health Sci Res. 3(10):117-120

Rendell JK, Gay T, Grasso JE, Baker RA, Winston JL (2000) The effect of denture adhesive on mandibular movement during chewing. J. Am. Dent Assoc 131: 981-986

Salman YM (2001) Effect of denture adhesives on the retention of maxillary complete denture. In: M.Sc. D thesis, College of Dentistry, University of Baghdad

Salman YM, Ibrahim IK (2005) Effect of denture adhesives on the retention of maxillary complete denture. J College Dentistry 17(1):30-34

Soman B, Bhatnagar S (2014) Adverse Effects of Drugs on Salivary Glands. Int J Dent Med Res 1(4):94-98

Turkyilmaz I (2010) One-year clinical outcome of dental implants placed in patients with type 2 diabetes mellitus: a case series. Implant Dent 19(4):323-329

Van Kampen F, Cune M, van der Bilt A, Bosman F (2003) Retention and postinsertion maintenance of bar-clip, ball and magnet attachments in 
mandibular implant overdenture treatment: an in vivo comparison after 3 months of function. Clin Oral Impl Res 14:720-26.

Yadav A, Yadav S (2005) Denture adhesives. Their stand in prosthodontics. J Indian Prosthodont Society 5(2):62-64

Yegin E, Akpinar YZ, Yavuz T, Aslan MA (2017) Effect of different denture adhesives on retention of complete dentures: an in vivo study. Journal of Adhesion Science and Technology 31(18):1-9

Yen HJ, Chen MS, Lin HN, Kuo SL, Juan PK, Liao PB (2013) Implant Retained Overdenture Improves the Retention and Stability by Using a Locator System in a Mandibular Edentulous patient: Case Report. J Prosth \& Implantology. 2(2):26-30

Submit your manuscript to a SpringerOpen ${ }^{\circ}$ journal and benefit from:

- Convenient online submission

- Rigorous peer review

- Open access: articles freely available online

- High visibility within the field

- Retaining the copyright to your article

Submit your next manuscript at $\boldsymbol{\nabla}$ springeropen.com 